DOI: https://doi.org/10.3897/arb.v30.e09

\title{
INVESTIGATION OF THE BASIC HAAR WAVELET- TRANSFORMATIONS IN THE PROBLEM OF DECRYPTION OF SPACE IMAGES ON DETECTION OF WASTE DISPOSAL FIELDS
}

\author{
Maretta Kazaryan $^{1}$, Mikhail Shahramanian ${ }^{2}$, Svetoslav Zabunov ${ }^{3}$ \\ ${ }^{1}$ Financial University under the Government of the Russian Federation; \\ e-mail:marettak@bk.ru \\ ${ }^{2}$ Research Institute AEROKOSMOS, 105064, Moscow, e-mail: 7283963@mail.ru. \\ ${ }^{3}$ Space Research and Technology Institute - Bulgarian Academy of Sciences, \\ e-mail: svetoslavzabunov@gmail.com
}

\begin{abstract}
In this paper, we study the use of orthogonal transformations, namely, the basic Haar wavelet transforms, for data processing of the Earth remote sensing.

The internal structure of orthogonal Haar transforms is considered. The Haar matrix is divided into blocks of the same type, so that parallelization of the computations is possible. The expediency of replacing the spectral components corresponding to the whole block (or several blocks) of the original matrix with zeros is asserted. Theoretical and experimental studies are carried out to improve the results of image classification (on the example of cluster analysis). The Haar wavelet expansion coefficients are used as indicators when decoding space images for the presence of waste disposal sites.

The aim of this paper is to describe the approach, on the basis of which an optimal method is established on a class of vectors with real components

$\mathrm{X}_{\Delta}=\left\{\bar{x}=\left(x_{0}, \ldots, x_{N-1}\right): \max _{\mathrm{k}}\left|x_{k-1}-x_{k}\right| \leq \Delta\right\}$, application of two-dimensional discrete Haar wavelet transformations in the problem of recognition of space images for the presence of waste disposal sites.

General methodology of research. The paper uses elements of mathematical analysis, wavelet analysis, the theory of discrete orthogonal transformations, and methods for decoding cosmic images.

Scientific novelty. Encoding by means of conversion is an indirect method, especially effective in processing of two-dimensional signals, in particular, space images used for remote sensing of the Earth.

We propose the approach that takes into account the structure of the wavelet-Haar matrix, while recognizing waste disposal fields by means of space images.

The article comprises the result of the experimental application of wavelet-Haar transformations for decoding of space images. We consider this case, both with and without the technique of taking into account the structure of the wavelet-Haar matrices.
\end{abstract}




\section{Introduction}

Modern photogrammetry is characterized by digitalization, i.e. wide introduction of information technologies and the creation of automatic and automated information systems for decoding of satellite imagery. It suggests the measuring of the coordinates of the corresponding points and the recognition of objects.

This article continues the research of the creation of an automated system for monitoring the territories for the presence of waste disposal sites (WDSs).

As a matter of fact, we speak about the application of the mathematical apparatus, namely, of wavelet analysis in the subsystem of detecting the unauthorized WDSs, while working with aerospace information, primarily for automated decryption. As different information technologies with multiple characteristics emerge, remote monitoring of various phenomena and objects is now quite possible and is widely used [1, 12, 22-28].

It is, first of all, the satellite systems for Earth observation and large flows of information that enter the scientific laboratories. This leads to the creation of new approaches and methods for organization of the work with information about remote sensing of the Earth (RS), as well as technologies for constructing remote monitoring systems.

The topic of wavelet analysis is quite in demand $[4-11,18,19]$. The wavelet transform is the decomposition of the original signal into wavelet functions using scaling and shift operations. The graphical representation of the result of the wavelet analysis is called wavelet coefficients. The accomplishment of an inverse transformation leads to a convolution of the wavelet coefficients and the wavelet function. If only a part of the coefficients is used for the inverse transformation, a filtered image is obtained, which is later used when recognizing the objects in the image.

There is a relationship between the values of the coefficients of wavelet decompositions and signal deviations $[18,19]$. This property is used when working with space images [12].

The visual analysis of wavelet decompositions allows identifying objects of different sizes. This is due to the fact that when the conversion and the shifts are performed in parallel, scaling also occurs. General patterns are determined when small scales are used. Local features in the image are revealed when large scales are used [20].

The use of the wavelet transform makes it possible to exclude from consideration small, minor objects that hinder the visualization of valuable objects in the image. The visualization of WDS, as is known, is carried out with the automated processing of the results of remote sensing of the Earth, as well as in the interactive processing of space images. 
When monitoring territories using remote sensing data for the presence of a WDS, one can use the properties of wavelet transforms under consideration.

To detect the changes in the area of study, a periodic monitoring of a fixed area is also necessary. So, in the course of time, it is necessary to identify changes in the terrain for the presence of WDS. When solving such a problem, external factors that interfere with the objective information gathering are in effect: the state of the atmosphere, the season, the position of the sensor, and so on.

The wavelet transform minimizes this effect and improves the accuracy of the decoding of the space image [16].

Let us specifically consider the Haar transformations as one of the varieties of wavelet transforms and carry out theoretical as well as practical studies on deciphering the space images (SI) for the presence of a WDS [20].

\section{Formulation of the problem}

The Haar functions belong to the class of piecewise-constant functions. They allow evaluating the local properties of the signals under study and are usually called Haar wavelets. Let us give the main definitions.

Definition 1.

$$
\begin{gathered}
\chi_{1}(t) \equiv 1 \\
\chi_{m j}(t)=\left\{\begin{array}{c}
2^{\frac{m-1}{2}}, \text { for } t \in\left[\frac{j-1}{2^{m-1}}, \frac{2 j-1}{2^{m}}\right) \\
-2^{\frac{m-1}{2}}, \text { for } t \in\left[\frac{2 j-1}{2^{m}}, \frac{j}{2^{m-1}}\right) \\
0 \text { in all other cases }
\end{array}\right.
\end{gathered}
$$

where $m=1,2, \ldots ; j=1, \ldots, 2^{m-1}$, and in case $j=2^{m-1}$, the right side of the segments is also considered closed on the right. When numbering functions by a single index $k$, it is assumed $k=2^{m-1}+j$.

This definition, as it is known, differs from Haar's definition of Haar values [2] at points of discontinuity, but the main property of the Haar system - the uniform aspiration of the Fourier-Haar series of $f(t)$ to $f(t)$ [10] is preserved.

Let's consider the Haar functions from the standpoint of applying them to wavelet analysis. It is known that Haar's functions are now also called Haar wavelets, since they can be described with the help of formal rules adopted in the theory of wavelet analysis $[18,19]$. The scaling function and the "Haar mother wavelet" coincide with the first and second functions respectively, of the considered system.

$$
\varphi(\theta)=\chi_{0}(\theta) \equiv 1, \quad \theta \in[0,1)
$$




$$
\psi(\theta)=\varphi(2 \theta)-\varphi(2 \theta-1)=\chi_{1}(\theta)=\left\{\begin{array}{l}
1, \theta \in\left[0, \frac{1}{2}\right) ; \\
-1, \theta \in\left[\frac{1}{2}, 1\right) .
\end{array}\right.
$$

Functions of the Haar system are determined according to the theory of wavelets by means of large-scale transformations and transfers of the "mother wavelet":

$$
\chi_{m k}(\theta)=\sqrt{2^{m}} \psi\left(2^{-m} \theta-k\right) ; m=0,1,2, \ldots ; k=0,1, \ldots, 2^{m}-1
$$

It is also known how to move from double numbering to single [19]

$$
n=2^{m}+k ; \quad m=0,1,2, \ldots, ; k=0,1, \ldots, 2^{m}-1
$$

There is also a mechanism for using the system of orthogonal Haar functions as the basis for the expansion of a continuous signal defined on an interval.

Haar series of one-dimensional signal $x(t), t \in[0, T)$ have the form

$$
x(t)=\sum_{n=1}^{\infty} c_{n} \chi_{n}\left(\frac{1}{T}\right)
$$

Here the coefficients are calculated by the formula:

$$
c_{n}=\frac{1}{T} \int_{0}^{T} x(t) \chi_{n}\left(\frac{1}{T}\right) d t
$$

The truncated Haar series are:

$$
x_{N}^{*}(t)=\sum_{n=0}^{N-1} c_{n} \chi_{n}\left(\frac{t}{T}\right)
$$

The latter possess the property of uniform, mean-square convergence and convergence in mean. These series are used to approximate signals described by integrable functions.

The mean square error of approximation for a finite number of orthogonal components of the Haar series is calculated by the formula:

$$
\sigma^{2}=\frac{1}{T} \int_{0}^{T}\left[x(t)-\sum_{n=0}^{N-1} c_{n} \chi_{n}\left(\frac{t}{T}\right)^{2}\right] d t
$$

Or with double numbering, the Haar series has the form:

$$
x(t)=c_{0}+\sum_{m=0}^{\infty} \sum_{k=0}^{2^{m}-1} c_{m k} \chi_{m k}\left(\frac{t}{T}\right)
$$

We consider the following problem connected with the structure of Haar functions [3].

As an example, let us consider the Haar matrix of order 8 . 


$$
F_{H}(8)=\frac{1}{\sqrt{8}}\left|\begin{array}{cccccccc}
1 & 1 & 1 & 1 & 1 & 1 & 1 & 1 \\
1 & 1 & 1 & 1 & -1 & -1 & -1 & -1 \\
\sqrt{2} & \sqrt{2} & -\sqrt{2} & -\sqrt{2} & 0 & 0 & 0 & 0 \\
0 & 0 & 0 & 0 & \sqrt{2} & \sqrt{2} & -\sqrt{2} & -\sqrt{2} \\
2 & -2 & 0 & 0 & 0 & 0 & 0 & 0 \\
0 & 0 & 2 & -2 & 0 & 0 & 0 & 0 \\
0 & 0 & 0 & 0 & 2 & -2 & 0 & 0 \\
0 & 0 & 0 & 0 & 0 & 0 & 2 & -2
\end{array}\right| \begin{aligned}
& \} \\
& \} H_{8}^{0} \\
& M H_{8}^{1} \\
& M H_{8}^{2} \\
& \\
& M H_{8}^{3}
\end{aligned}
$$

The notation system is as follows: $M H_{8}^{k}-$ a rectangular submatrix of the size $8 \times 2^{k-1}$. This submatrix is formed from the Haar functions of rank $\mathrm{r}$, where $2^{k-1} \leq r<2^{k}, k=1,2,3$.

The Haar matrix of any order $N=2^{n+1}(n \geq 0)$ can be decomposed into submatrices $M H_{2^{n+1}}^{k}, k=1,2, \ldots, n+1$.

Each submatrix is formed from the Haar functions of rank $r, 2^{k-1} \leq r<2^{k}$. Known matrix operator $\mathfrak{I}$, which makes it possible to create these submatrices with the help of a recurrence relation:

$$
\Im[M]=M \otimes\left[\begin{array}{ll}
1 & 0 \\
0 & 1
\end{array}\right]=\left[\begin{array}{ccc}
{[M]} & \vdots & {[0]} \\
\cdots & \vdots & \cdots \\
{[0]} & \vdots & {[M]}
\end{array}\right]
$$

Notation system: $M$ is a dimension matrix $m \times p ; \otimes-$ kronecker product. After the action of the operator $\mathfrak{I}$, we obtain a matrix of dimensions $2 m \times 2 p$; It is known that:

$$
M H_{2^{n+1}}^{k}=\mathfrak{I}\left[M H_{2^{n}}^{k-1}\right] k=2, \ldots, n+1
$$

The rectangular matrix $M H_{2^{n+1}}^{k}$ for any $\mathrm{n}$ has the following form: 


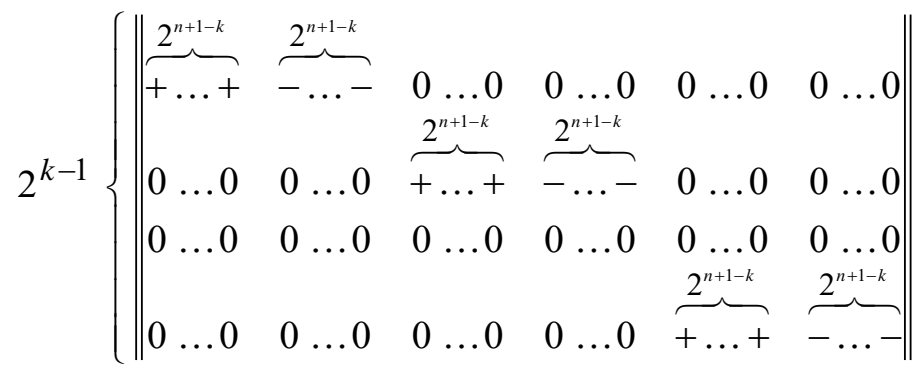

Notation system: + means $+\sqrt{2^{k-1}} ;-$ means $-\sqrt{2^{k-1}}$; where $k=2, \ldots, n+1$. Let $F=\left\|\varphi_{j}(i)\right\|_{j, i=0, N-1}$ discrete orthogonal transformation (DOT) Haar matrix and let $\bar{x} \in X_{\Delta}$, where $\mathrm{X}_{\Delta}=\left\{\bar{x}=\left(x_{0}, \ldots, x_{N-1}\right): \max _{k}\left|x_{k-1}-x_{k}\right| \leq \Delta\right\}$. To determine the most informative elements, let's consider the following optimization problem. Find $y_{j} \rightarrow$ extr under condition $\bar{x} \in X_{\Delta}$, where:

$$
y_{j}=x_{0} \varphi_{j}(0)+x_{1} \varphi_{j}(1)+\ldots+x_{N-1} \varphi_{j}(N-1)
$$

For definiteness, let us consider the maximum problem. $y_{j} \rightarrow \max$ under conditions:

$$
\begin{aligned}
& \left|x_{k-1}-x_{k}\right| \leq \Delta, k=\overline{1, N-1} \text { where } y_{j}=\sum_{i=0}^{N-1} x_{i} \varphi_{j}(i) \\
& j \text {-fixed integer } j=\overline{1, \ldots, N-1} .
\end{aligned}
$$

Algorithm for solving the problem (1): In solving this problem, we use the optimality principle in dynamic programming [21]. The initial problem splits into iterative steps, at each step a solution is sought in accordance with the principle of optimality. The decision-making procedure will be carried out starting at the end and going to the beginning.

Let $\hat{x}_{0}, \ldots, \hat{x}_{N-2}$ in (1) are optimally chosen. Then the last step will be to find the optimal value of the component $x_{N-1}$. Given that $\left|x_{N-2}-x_{N-1}\right| \leq \Delta$ we can assume $\hat{x}_{N-1}=\hat{x}_{N-2}+\Delta \operatorname{sign} \varphi_{j}(N-1)$.

The solution of problem (16) is presented: 


$$
\begin{aligned}
& \hat{y}_{j}=\hat{x}_{0} \varphi_{j}(0)+\hat{x}_{1} \varphi_{j}(1)+\ldots \\
& +\hat{x}_{N-2} \varphi_{j}(N-2)+\left(\hat{x}_{N-2}+\Delta \operatorname{sign} \varphi_{j}(N-1)\right) \varphi_{j}(N-1)= \\
& =\hat{x}_{0} \varphi_{j}(0)+\hat{x}_{1} \varphi_{j}(1)+\ldots+\hat{x}_{N-2}\left(\varphi_{j}(N-2)+\varphi_{j}(N-1)\right)+\Delta \varphi_{j}(N-1)
\end{aligned}
$$

Let us now turn to the following problem for a maximum: $y_{j} \rightarrow \max$ on condition:

$$
\left|x_{k-1}-x_{k}\right| \leq \Delta, k=\overline{1, N-2}
$$

where

$$
y_{j}=\sum_{i=0}^{N-3} x_{i} \varphi_{j}(i)+x_{N-2}\left[\varphi_{j}(N-2)+\varphi_{j}(N-1)\right]+\Delta\left|\varphi_{j}(N-1)\right|
$$

Let us assume that $\hat{x}_{0}, \ldots, \hat{x}_{N-3}$ in (19) are optimal. Then

$$
\hat{x}_{N-2}=\hat{x}_{N-3}+\Delta \operatorname{sign}\left(\varphi_{j}(N-2)+\varphi_{j}(N-1)\right)
$$

The solution of problem (19) is

$$
\begin{aligned}
& \hat{y}_{j}=\hat{x}_{0} \varphi_{j}(0)+\hat{x}_{1} \varphi_{j}(1)+\ldots+\hat{x}_{N-3} \varphi_{j}(N-3)+ \\
& +\left[\hat{x}_{N-3}+\Delta \operatorname{sign}\left[\varphi_{j}\left(N-2+\varphi_{j}(N-1)\right)\right]\right]\left[\varphi_{j}(N-2)+\varphi_{j}(N-1)\right]+\Delta\left|\varphi_{j}(N-1)\right|= \\
& =\hat{x}_{0} \varphi_{j}(0)+\hat{x}_{1} \varphi_{j}(1)+\ldots+\hat{x}_{N-3}\left(\varphi_{j}(N-3)+\varphi_{j}(N-2)+\varphi_{j}(N-1)\right)+ \\
& +\Delta\left|\varphi_{j}(N-2)+\Delta \varphi_{j}(N-1)\right|+\Delta\left|\varphi_{j}(N-1)\right|
\end{aligned}
$$

Continuing this process step by step, in the end we will have

$$
\max _{x \in X_{\Delta}} y_{j}=x_{0} \sum_{i=0}^{N-1} \varphi_{j}(i)+\Delta \sum_{m=1}^{N-1}\left|\sum_{i=m}^{N-1} \varphi_{j}(i)\right| \quad, \quad j=\overline{1, N-1}
$$

For the Haar matrix, by virtue of orthogonality, we have:

$$
\varphi_{j}(0)+\varphi_{j}(1)+\ldots+\varphi_{j}(N-1)=0, \quad j=\overline{1, N-1}
$$

Taking into account relations (22) and (23), we obtain:

$$
\max _{x \in X_{\Delta}} y_{j}=\Delta \sum_{m=1}^{N-1}\left|\sum_{i=0}^{m-1} \varphi_{j}(i)\right| \quad, \quad j=\overline{1, N-1}
$$

If we consider the problem to a minimum, we have: 


$$
\min _{x \in X_{\Delta}} y_{j}=-\Delta \sum_{m=1}^{N-1}\left|\sum_{i=0}^{m-1} \varphi_{j}(i)\right|, j=\overline{1, N-1}
$$

In general

$$
\max _{x \in X_{\Delta}}\left|y_{j}\right|=\Delta \sum_{m=1}^{N-1}\left|\sum_{i=0}^{m-1} \varphi_{j}(i)\right|, j=\overline{1, N-1}
$$

This relation leads to the following assertion.

\section{Statement:}

The least informative elements, which can be zeroed out in the future, are the elements of the last bundle of vector $\bar{y}$.

Proof. Let $F=F_{H}(N)$ be the matrix of order

$$
N=2^{n+1}(n \geq 0), \bar{x} \in X_{\Delta}, \bar{y}=F_{H}(N) \bar{x}=\left(y_{0}, \ldots, y_{N-1}\right)^{T} .
$$

Based on (26) and starting from the form of the matrix $M H_{2^{n+1}}^{k}$, we have for

$$
\begin{aligned}
& j=2^{k-1}, \ldots, 2^{k}-1: \\
& \frac{1}{\Delta} \max _{\bar{x} \in X_{\Delta}}\left|y_{j}\right|=\frac{1}{\sqrt{N}}\left[\sqrt{2^{k-1}}+2 \sqrt{2^{k-1}}+\ldots+2^{n+1-k} \sqrt{2^{k-1}}+\left(2^{n+1-k}-1\right) \sqrt{2^{k-1}}+\left(2^{n+1-k}-2\right) \sqrt{2^{k-1}}+\ldots+\sqrt{2^{k-1}}\right]= \\
& =\frac{\sqrt{2^{k-1}}}{\sqrt{N}}\left[1+2+\ldots+2^{n+1-k}+\left(2^{n+1-k}-1\right)+\ldots+1\right]=\frac{\sqrt{2^{k-1}}}{\sqrt{N}} 2^{2(n+1-k)}=\frac{N^{3 / 2}}{\sqrt{2^{3 k+1}}}
\end{aligned}
$$

It follows that the least informative elements are the elements of the last packets of vector $\bar{y}$, so they can be reset to zero when the image or space image (SI) is further processed.

\section{Experimental research}

Let's use the theoretical studies and carry out an experiment related to the application of the cluster analysis algorithm to decipher the SI for the presence of WDS on the basis of the soil.

The state of the soil cover largely depends on anthropogenic factors industrialization, urbanization, contamination with solid and liquid waste, soil poisoning with pesticides, etc.

As an experimental part of this article, we investigate the problem of using wavelets-Haar for space images obtained from the Landsat artificial satellite (AS), in aerospace monitoring of solid domestic waste. The experiment will consider multispectral imagery, for example, one received from Landsat 4-5 TM satellites for a given observation period (OP), usually at least 10 years long, as well as the data on the amount of precipitation in the study area for the same period. Photographs (SI) 
should be geo-linked, atmospherically corrected and without clouds. In the experiment, bands $1-7$ are used.

Consider one of the methods for processing of multispectral images that improves the results of decoding - the method of applying orthogonal transformations (Fourier transform, Walsh, Haar, and Karunen-Loeve). In particular, we consider the wavelet-Haar transformation. We also verify assertion 1, which was proved earlier in this article.

It is known [12] that the bands of multispectral images very often turn out to be correlated. The reason for this correlation may be:

- Correlation of spectral properties of objects (this is possible, for example, with low reflectivity of vegetation cover in the visible part of the spectrum);

- Topography (the level of shading due to topographic features can be considered the same in all ranges of registration of reflected solar radiation);

- Overlapping of registration ranges (ideally this factor is excluded when designing the sensor, but in practice this is not always the case).

Such a correlation leads to the emergence of redundant information. The goal that is in front of us in the experiment is to try to get rid of the redundant information with minimal errors using the wavelet-Haar transform property of the transformations stated in Statement 1. First, we consider the representation of a space image by means of orthogonal transformations. Next, let us consider the selection of the most informative coefficients or the selection of certain features by applying wavelet-Haar transformations and performing the filtering in the local area of the image, i.e. we will make the transition to a new basis for measurements in fixed spectral channels.

The transformation matrix of the orthogonal transform under investigation is fixed for a given type of sensor and survey system, therefore, for each new surveying system; new coefficients of the discrete orthogonal transformations (DOT) must be calculated.

Let us consider the point of the proposed method. The physical justification for it is as follows. In multispectral imaging systems, the image is formed in accordance with the reflection from objects of electromagnetic energy in narrow spectral regions.

The image in certain channels fixes the reflection of the spectral brightness of the original object in a given range of the electromagnetic spectrum.

Multispectral image

$$
P_{M}=\left(\begin{array}{ccc}
\bar{P}_{11} & \ldots & \bar{P}_{1 M} \\
\vdots & \ddots & \vdots \\
\bar{P}_{N 1} & \ldots & \bar{P}_{N M}
\end{array}\right)
$$

consists of $k$ images $P^{(k)}$, each of which represents the values of the brightness measured in narrow spectral regions ( $k$-number of channels of the survey system). 
Vector $\bar{P}_{i j}=\left(p_{i j}^{1}, p_{i j}^{2}, \ldots, p_{i j}^{k}\right)$ contains the brightness values of the elements $P_{i j}$ in each channel of the filming system.

For different objects, the spectral brightness in different ranges of the electromagnetic spectrum, although different, is strongly correlated. Measurements in narrow spectral regions (bands) performed by a multispectral imaging system do not eliminate the correlation dependence. Thus, the measurement system does not form an orthogonal basis. Orthogonal transformations make a transition from the space of measurements of the spectral brightness of objects to the space of attributes associated with the properties of a given class of objects.

So, the experiment consists of two steps: the first one is the application of the orthogonal transformation to the original image, which will allow decorrelating the component image vectors and reducing the dimensionality of the image; the second is to build a learning classifier for the task of pattern recognition.

Let us consider the implementation of the first part, namely, the selection of characteristics.

We consider the type of object that undergoes changes in the presence of solid household waste: clean soil, i.e. we are interested in such a characteristic sign as brightness.

The purpose of experimental studies is to assess the accuracy of soil deciphering based on comparing the results of visual decoding of the original image and the image obtained with the use of the ADT. Then, based on comparing the results of classification without learning, using the $k$-means algorithm for this image, and on the image with orthogonal transformation. After segmenting the selected SIs, we define homogeneous clusters.

\section{Description of the algorithm}

The further numerical algorithm is defined as follows.

Let us describe the algorithm first for the original one-dimensional vector $x$. The transition to a two-dimensional image is accomplished by applying the experimental results to the rows and columns of the original image, i.e. the SIs, will be discussed in detail below.

Let $x=\left(x_{0}, x_{1}, \ldots, x_{N-1}\right)$ be the initial data vector, considered as the realization of some random process with certain properties.

$F$ - discrete orthogonal transformation (wavelet-Haar transform);

$F^{-1}$ - inverse transformation;

$k$ - number of discarded items, $k=\frac{N}{m}$;

$m$ - the number of stored items in the new coordinate system; 
$S$ - matrix of dimension choice $m \times N$ ранга $m, 1 \leq m \leq N$;

$W$ - dimension recovery matrix $N \times m$;

$\rho$ - some metric.

The task of selecting informative elements consists in choosing F, S, W so that

$$
\rho\left(x, F^{-1} W S F x\right) \rightarrow \min
$$

The matrices $F_{0}, S_{0}, W_{0}$ lead to the indicated minimum and are called respectively the optimal basis matrices, optimal choice matrices and optimal recovery matrices.

Substantively, problem (30) reduces to the following. The original vector $x$ of dimension $N$ undergoes an orthogonal transformation $F$, which leads to a new, more convenient coordinate system. Then, using the selection matrix $S, m$ samples of the signal in the new coordinate system are selected. These samples are intended for image recognition. If necessary, "extrapolation" (restoring the dimension) of these samples by means of the matrix $W$ is carried out. Then, by means of the orthogonal transformation, the original signal is restored.

When solving the SIs decoding problem, we consider a simpler problem. Namely, we fix the transformation $F$ and take $W=S^{T}$. Then in (30) the minimization is performed only over $S$.

The value $\rho\left(x, F_{0}{ }^{-1} W_{0} S_{0} F_{0} x\right)$ is called the recovery error level.

Comment. Let $S$ be a matrix of the form $\left(I_{k}: 0\right), W=S^{T}, \rho$ - the rootmean-square criterion, then in expression (30) the optimization is carried out only with respect to F. In this case, the optimal basis is the Karunen-Loeve basis [3]. The Karunen-Loeve basis leads to uncorrelated components, but requires a large volume of operations $-o\left(N^{3}\right)$.

In view of our assertion 1, we can list the main steps of the algorithm under consideration.

Let $x=\left(x_{0}, x_{1}, \ldots, x_{N-1}\right)$ be the initial data vector from some metric $\operatorname{space}(X, \rho), F$ is an orthogonal matrix of order $\mathrm{N}$ (wavelet-Haar);

The algorithm is implemented in three steps.

1. The vector $x=\left(x_{0}, x_{1}, \ldots, x_{N-1}\right)$ undergoes a transformation $F$ :

$$
y=F x=\left(\begin{array}{c}
y_{0} \\
y_{1} \\
\vdots \\
y_{N-1}
\end{array}\right)
$$

2. The vector $y$ is replaced by the operator of choice $S$ by a smaller vector $\hat{y}$ : 


$$
\hat{y}=S y=\left(y_{0}, y_{1}, \ldots, y_{m-1}\right),
$$

which must be further deciphered.

The matrix $S$ of dimension $m \times N$ has the form:

$$
S=\left(\begin{array}{ccccccc}
1 & 0 & 0 & 0 & 0 & 0 & 0 \\
0 & 1 & 0 & 0 & 0 & 0 & 0 \\
\vdots & \vdots & \ddots & \vdots & \vdots & \vdots & \vdots \\
0 & 0 & 0 & 1 & 0 & 0 & 0
\end{array}\right)
$$

$k$-compression ratio of the original signal, $k=\frac{N}{m}$;

3. On the receiving side, the resulting vector $\hat{y}$ is complemented to the dimension $N$ by means of the operation

$$
\tilde{y}=S^{T} \hat{y}=\left(y_{0}, y_{1}, \ldots, y_{m-1}, 0, \ldots, 0\right) .
$$

4. The vector $\tilde{y}$ undergoes a reverse transformation $\mathrm{F}^{-1}$ i.e.

$$
\hat{x}=F^{-1} \tilde{y},
$$

which restores the original data vector with an error $\varepsilon=\rho(x, \hat{x})$.

The problem is to determine such a choice of the spectral components replaced by zero, which ensures a minimum of error for a given $k$.

It follows from Assertion 1 that in the case of a wavelet-Haar transformation, it is necessary to replace the last pack of blocks with zeros. images.

In more detail, let us consider in detail the case of two-dimensional space

Entering the input system of the original image of dimension $N \times N$, we represent them in the form of their scans, namely the $m=N^{2}$ element vector, i.e. consider a one-dimensional signal.

The coding process is performed in two stages.

1. By means of the transformation $F m$, the m-dimensional space of the original vectors $f$ is mapped into the m-dimensional spectral space of vectors $\hat{f}$.

2. The transition to the $k$-dimensional $(\mathrm{k}<\mathrm{m})$ space by means of the operator $S$ reduces the dimension of the vector $\hat{f}$, i.e. the most informative spectral components of the vector $\hat{f}$ are selected.

The most informative are those spectral components whose transmission will allow us to obtain in the decoder an estimate of $g$ of the original vector $f$ with the minimum possible distortions determined by the chosen metric $\rho(f, g)$. 
The decoding process is performed in two stages:

1. By means of the operator $W$, a filtering of the noisy truncated vector $\hat{f}$ and a transition from the $k$-dimensional to the $m$-dimensional space of the spectral components are carried out.

2. Through the $F^{-1}$ operator m-dimensional space of spectral components is mapped into $m$-dimensional space of initial vectors.

Let us give a photogrammetric interpretation of the described algorithm, taking into account the research related to the WDS and space images, respectively. The Haar transformation in matrix form can be written as $Y=F X, \quad X=F^{-1} Y$, where $X$ and $Y$ are matrices of the halftone image size in the luminance and frequency space, $F$ and $F^{-1}$ are linear operators $N \times N$ of the size of the direct and inverse Haar transform for the corresponding images of $X$ and $Y$.

The matrix $X$ is obtained by changing the size of the original matrix $X$ from $N \times N$ to $m \times m$, where $N=2^{n}, n=1,2, \ldots$ change in spatial resolution.

To do this, an interpolation of the functional $z=X(i, j)$ defined by a grid of values $i=1 \ldots m, j=1 \ldots m$ with a step $h=1$ ( $\mathrm{m}$ values along the abscissa and ordinate axes) into the functional $z=X(i, j)$, given by a grid of values $i=1 \ldots m, j=1 \ldots m$ with step $h=(m-1) / N(N$ values along the abscissa and ordinate axes). Compression of the matrix $Y$ is provided by the compression matrix $Y^{\prime}=S F X$ (selection matrix) $S$.

The effect of the operator $S$ on $Y$ acting as a low-pass filter (from 1 to $\mathrm{m}$ ) leads to another result of the direct conversion: $Y^{\prime}=S F X$.

As a result of the inverse transformation of the $\left(F^{\prime}\right)^{-1}$ matrix $Y^{\prime}$ signal $X^{\prime}=\left(F^{\prime}\right)^{-1} Y^{\prime}$ is restored with accuracy

$$
\varepsilon_{1}=\rho_{l_{2}}\left(X, X^{\prime}\right)=\sqrt{\frac{1}{N^{2}} \sum_{i=1}^{N} \sum_{j=1}^{N}\left(x_{i j}-x_{i j}^{\prime}\right)^{2}},
$$

$l_{2}$ - standard-mean-square norm; $\varepsilon_{1}$ - error of restoring a two-dimensional signal.

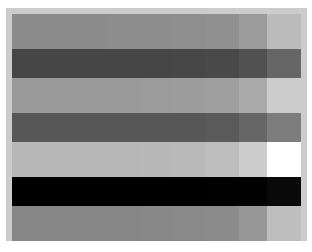
0.0198
0.0198
0.0198
0.0198
0.0199
0.0130
0.0130
0.0131
0.0131
0.0131
0. 아리
0. 0다미
0.0릴
0. 0달
0.0812
0.0147
0.0147
0.0147
0.0147
0.0148
0. 0238
0.0838
0.0839
0. 0839
0. 0839
0.0064
0.0064
0.0064
0.0064
0.0064
0.0193
0. 0193
0.0193
0.0193
0.0194 


$\begin{array}{llll}0.0199 & 0.0202 & 0.0218 & 0.0243 \\ 0.0132 & 0.0133 & 0.0141 & 0.0161 \\ 0.0213 & 0.0215 & 0.0286 & 0.0259 \\ 0.0148 & 0.0150 & 0.0161 & 0.0183 \\ 0.0241 & 0.0244 & 0.0259 & 0.0308 \\ 0.0064 & 0.0065 & 0.0066 & 0.0072 \\ 0.0195 & 0.0197 & 0.0208 & 0.0245\end{array}$

(a1)

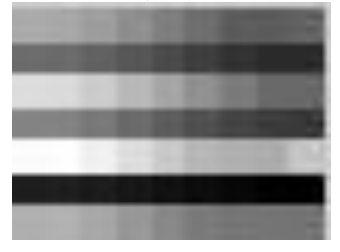

0.1156
0.0839
0.1418
0.0968
0.1567
0.0448
0.1285

(b1)

$\begin{array}{llll}0.1151 & 0.1098 & 0.1016 & 0.0934 \\ 0.0831 & 0.0786 & 0.0788 & 0.0667 \\ 0.1406 & 0.1389 & 0.1838 & 0.1288 \\ 0.0957 & 0.0908 & 0.0833 & 0.0761 \\ 0.1590 & 0.1515 & 0.1413 & 0.1311 \\ 0.0445 & 0.0487 & 0.0408 & 0.0375 \\ 0.1201 & 0.1248 & 0.1063 & 0.0984\end{array}$

$\begin{array}{llll}0.0851 & 0.0760 & 0.0757 & 0.0793 \\ 0.0604 & 0.0543 & 0.0507 & 0.0508 \\ 0.1028 & 0.0914 & 0.0825 & 0.0816 \\ 0.0693 & 0.0634 & 0.0592 & 0.0570 \\ 0.1281 & 0.0187 & 0.1271 & 0.1299 \\ 0.0349 & 0.0323 & 0.0897 & 0.0284 \\ 0.0913 & 0.0887 & 0.0884 & 0.0880\end{array}$

(a2)

(b2)

Fig. 1. Recovery errors: 1) $\varepsilon_{1}$; 2) $\varepsilon_{2}$; on different channels and at different compression ratios; $b$ ) matrices

We estimate the recovery errors (without the action of Statement) $\varepsilon^{\prime}{ }_{1}, \varepsilon^{\prime}{ }_{2}$ (under the action of the Statement) for the Haar transformation with different compression coefficients $k$ and on different channels of the original image $X$ of the litter area (landfill Kuchino, August 2011). We set $n=10$. In Fig. 1 shows the matrices $E_{l}=\left[\varepsilon_{1}(i, j)\right], E_{2}=\left[\varepsilon_{2}(i, j)\right]$ of sizes $l \times(N-1)$. We see that the maximum accuracy is observed on the 6 (thermal) bands and it varies little with compression. Matrices $E_{1} \approx E_{1}^{\prime}$ and the elements of the matrix $E_{2}^{\prime}$ are on the average larger than $E_{l}$ for a given value of $k$. The smaller $k$, the smaller the recovery error.

In Fig. $2-$ an example of signal reconstruction for $n^{\prime}=n / 2=5$ is given. It can be seen from figure (e) that an increase in the spatial resolution and a decrease in the compression ratio have little effect on the recovery result. In other words, the image of littering can be restored both with preservation or even reduction of the spatial resolution, and at its strong compression. This is due to the fact that the litter texture is characterized by a random, random spatial distribution of pixel brightness. 


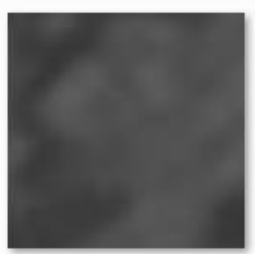

1

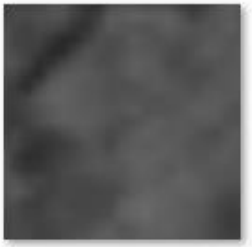

5

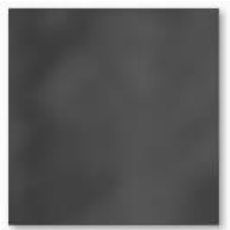

1

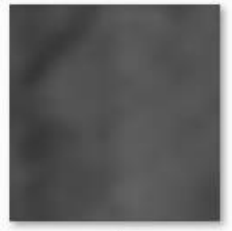

5

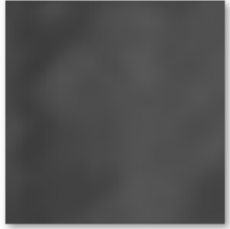

1

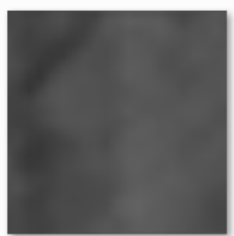

5

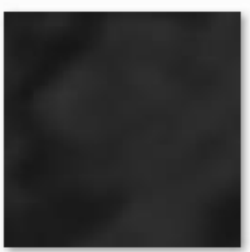

2

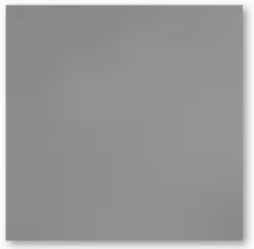

6

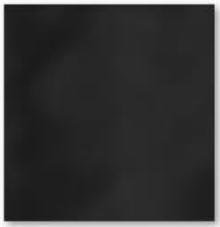

2

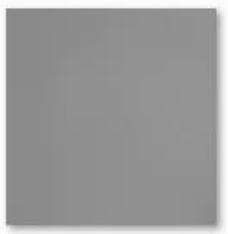

6

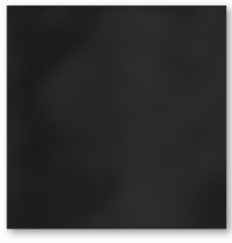

2

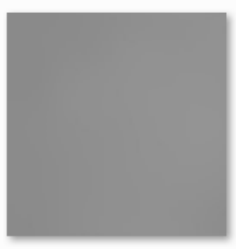

6

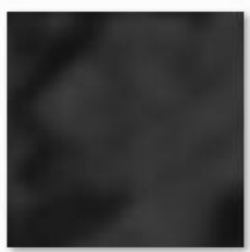

3

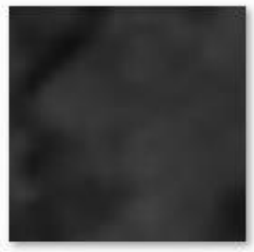

7

(a)

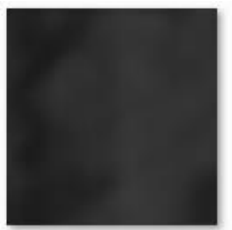

3

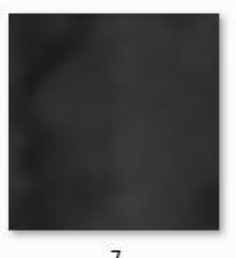

(b)

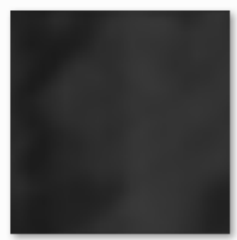

3

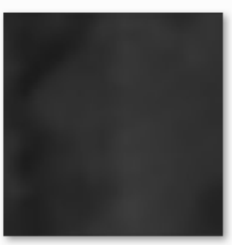

7

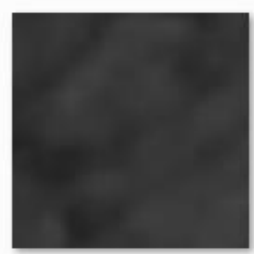

4

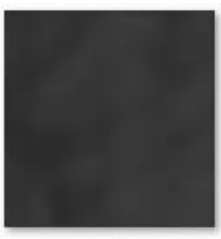

4

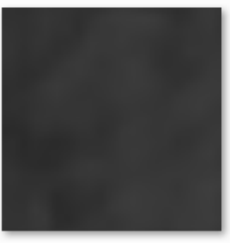

4

(c) 


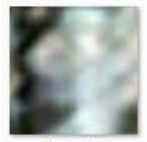

123

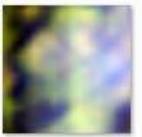

136

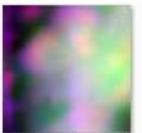

167

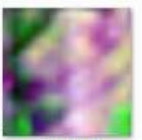

247

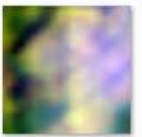

356

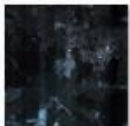

123

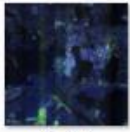

136

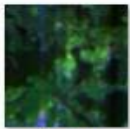

167

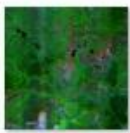

247

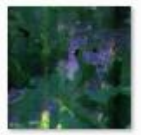

356

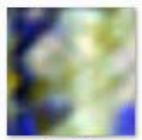

124

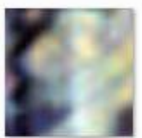

137

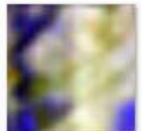

234

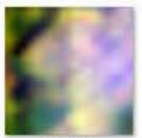

256

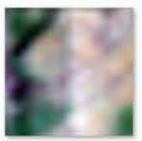

357

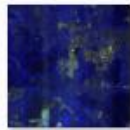

124

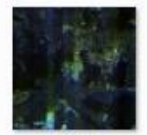

137

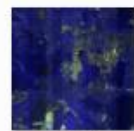

234

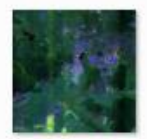

256

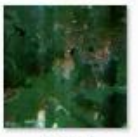

357

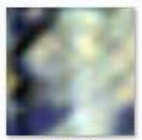

125

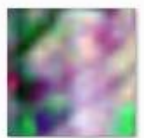

145

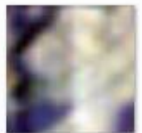

235

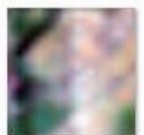

257

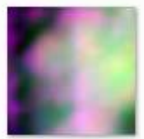

367

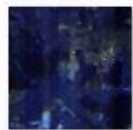

125

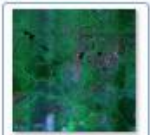

145

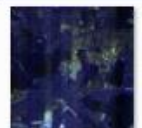

235

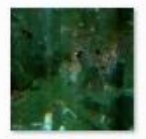

257

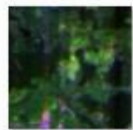

367

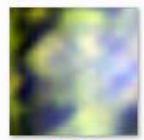

126

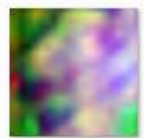

146

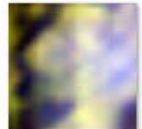

236

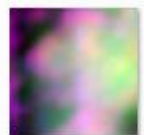

267

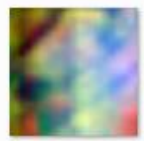

456

(d)

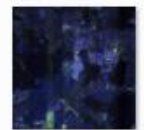

126

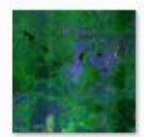

146

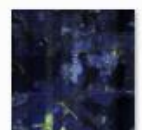

236

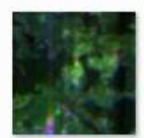

267

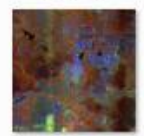

456

(e)

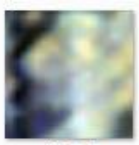

127

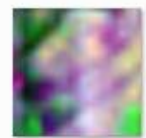

147

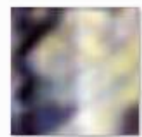

237

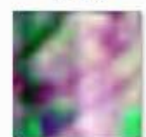

345

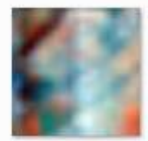

457

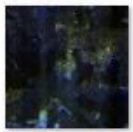

127

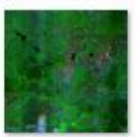

147

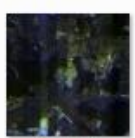

237

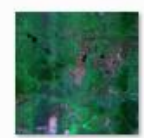

345

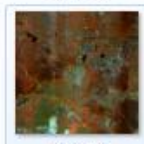

457

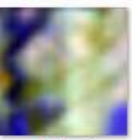

134

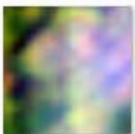

156

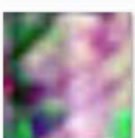

245

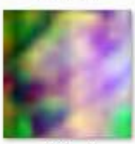

346

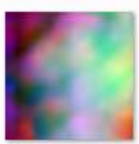

467

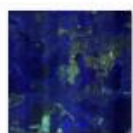

134

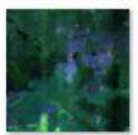

156

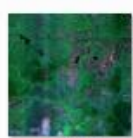

245

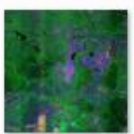

346

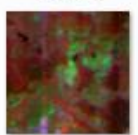

467

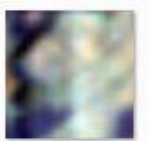

135

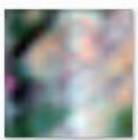

157

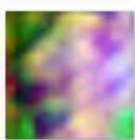

246

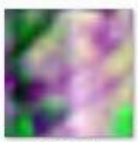

347

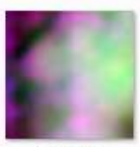

567

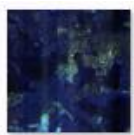

135

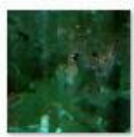

157

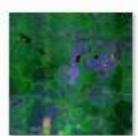

246

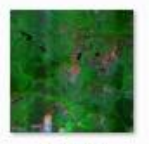

347

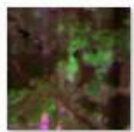

567 


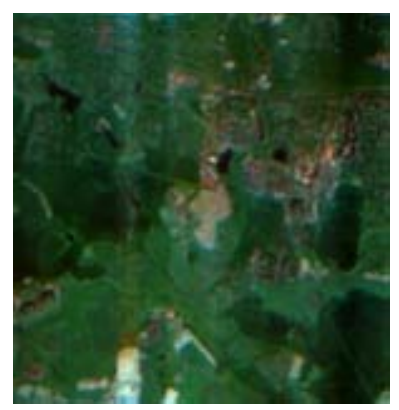

$(f 1)$

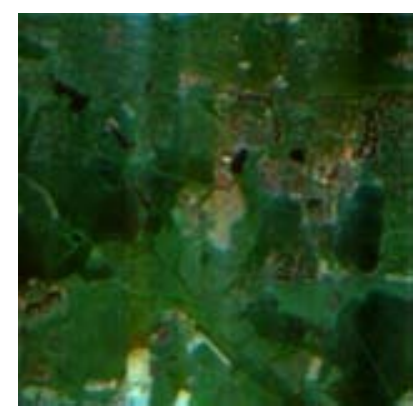

$(f 2)$

Fig.2. An example of Haar transforming the litter image:

a) source images (with increasing spatial resolution, $n=10$ );

b) Haar transformation with contraction $\left(n^{\prime}=5\right)$;

c) Haar transformation with contraction and $S\left(n^{\prime}=5\right)$;

d) composites of transformations (combination of different channels, $\left.n=8, n^{\prime}=2\right)$;

e) the best transformation (combination [3 5 7]);

f) examples of images $\left(1-n=8, n^{\prime}=2,2-n=10, n^{\prime}=3\right)$.

\section{Conclusions}

In this paper, the Haar wavelet transforms used in the recognition of space images are studied. The assertion about the determination of the selection matrix for a given type of transformation is proved.

An experiment has been carried out that confirms the validity of the asserted statement when decoding space images. This task is included as a component module of the project for aerospace monitoring of WDS facilities. The principle of optimality in dynamic programming, elements of mathematical analysis, the theory of discrete orthogonal transformations, as well as photogrammetric bases of information representation in space images are used in the work.

\section{References}

1. Kazaryan, M. L., M. A. Schahramanian, A.A. Richter. Space monitoring of the Earth and Haar wavelet transform. Future Communication Technology and Engineering, Chapter 61, (ed. Kennis Chan) CRC Press 2015, 291-94. Print ISBN: 978-1-13802777-0, eISBN: 978-1-315-69045-2.

2. Haar, A. Zur Theoria der orthogonalen Funktionsysteme. Math. Fnn. 1910, 69, 331-71.

3. Pratt, W. Digital image processing. M .: Mir, 1982, 312 p.

4. Hyvarinen, A. and Oja, E. Independent component analysis: Algorithms and applications. Neural Networks, 2000, 13, 4-5, 411-430. 
5. Cichocki, C., A. Amari. Adaptive blind signal and image processing: Learning algorithms and applications. Wiley, 2002. 555 p.

6. Vincent, E., R. Gribonval, C. Fevotte. Performance Measurement in Blind Audio Source Separation”, IEEE Trans. on Speech and Audio Processing, 2006, 14, 4, 1462-69.

7. Percival, D., Walden A. Wavelet methods for time series analysis. London: Cambridge University Press, 2000, 594 p.

8. Donoho, D., Johnstone I. Adapting to unknown smoothness via wavelet shrinkage. J. Amer. Statist. Assoc., 1995, 90, 1200-24.

9. Strang, G., Nguyen T. Wavelets and Filter Banks. Boston: Wellesley-Cambridge Press, $1996,512 \mathrm{p}$.

10. McQuarrie, A., Chin-Ling Tsai. Regression and time Series Model Selection. London: World Scientific Publishing, 1998. 455 p.

11. Redfern, A. L., G. T. Zhou. A root method for Volterra systems equalization. IEEE Signal Processing Letters. 1998, 5, 11, 285-288.

12. Robert, A. Showengerdt. Remote sensing / Models and Methods for Image processing. Burlington: Elsevier INC, 2007. 560 p.

13. Aristov, M. A. Monitoring of solid waste landfills and detection of spontaneous garbage disposal according to space survey data. GeoProfil.ru. № 2.

14. Pogorelov, A. V., S. V. Dulepa, D.A. Lipilin. Experience of space monitoring of landfills in the territory of the Krasnodar Territory. Geomatika, 2013, 4, 64-71.

15. Aleksandrovna, L. N., M. L. Glinsky, A. A. Zubkov, V. V. Danilov, and L .G. Chertkov. Monitoring of the state of the subsoil on the LRW burial site. URL: http://www.atomic-energy.ru/articles/2012/02/20/31086

16. Brovkina, O. V. Remote monitoring of anthropogenic disturbances in the taiga zone of the Northwest of Russia / dissertation, 2011, 125 p.

17. Yannikov, I. M., M. V. Sleptsova, K. K. Krivoshapkin. Organization of biomonitoring of chemically hazardous objects and landfills with the use of identification polygons. Bulletin of the NEFU M.K. Ammosov, Yakutsk, 2013, 15-25.

18. Chui, C. K. Wavelets: A Mathematical Tool for Signal Analysis. SIAM, Philadelphia, 1997.

19. Daubechies, I. Ten Lectures on Wavelets. SIAM, Philadelphia, 1992.

20. Gonsales, R. C., R .E. Woods, and S. L. Eddins. Digital Image Processing using Matlab, Pearson Prentice Hall, Upper Saddle River, NJ, 2004.

21. Korolyuk, V. S., N. I. Portenko, A. V. Skorokhod, A.F. Turbine et al. A handbook on probability theory and mathematical statistics. M.: Science. The main edition of physics and mathematics, 1985, $640 \mathrm{p}$.

22. Nedkov, R. Orthogonal Transformation of Segmented Images from the Satellite Sentinel2. Comptes rendus de l'Acad'emie bulgare des Sciences, 2017, 70, 5, 687-92. "Prof. Marin Drinov" Publishing House of Bulgarian Academy of Scinces, ISSN 13101331.

23. Nedkov, R. Quantitative Assessment of Forest Degradation after Fire Using Ortogonalized Satellite Images from Sentinel-2. Comptes rendus de l'Academie Bulgare des Sciences, 2018, 71, 1. "Prof. Marin Drinov" Publishing House of Bulgarian Academy of Scinces, ISSN 2367-5535. 
24. Nedkov, R. Normalized Differential Greenness Index for Vegetation Dynamics Assessment. Comptes rendus de l'Acad'emie bulgare des Sciences, 2017, 1143-46, 70, 8. "Prof. Marin Drinov" Publishing House of Bulgarian Academy of Scinces, ISSN 1310-1331.

25. Nedkov, R., E. Velizarova, I. Molla, and K. Radeva. Application of remote sensing data for forest fires severity assessment. Proc. SPIE 10790, Earth Resources and Environmental Remote Sensing/GIS Applications IX, 107901U (9 October 2018), 10790, SPIE, 2018, DOI:10.1117/12.2325742.

26. Radeva, K., R. Nedkov, and A. Dancheva. Application of remote sensing data for a wetland ecosystem services assessment in the area of Negovan village. Proc. SPIE 10783, Remote Sensing for Agriculture, Ecosystems, and Hydrology XX, 107830Y (10 October 2018); 10783, SPIE, 2018, DOI:10.1117/12.2325767.

27. Stankova, N., R. Nedkov. Monitoring forest regrowth with different burn severity using aerial and Landsat data. Geoscience and Remote Sensing Symposium (IGARSS), 2015 IEEE International, IEEE, 2015, 2166-69. ISBN: 978-1-47997929-5, ISSN 2153-7003, DOI:10.1109/IGARSS.2015.7326233.

28. Avetisyan D., R. Nedkov. Determining the magnitude and direction of land cover changes in the semi-natural areas of Haskovo Region, Southeast Bulgaria. Geoscience and Remote Sensing Symposium (IGARSS), 2015 IEEE International, IEEE, 2015, 4637-40. DOI:10.1109/IGARSS.2015.7326862.

\title{
ИЗСЛЕДВАНЕ НА ОСНОВНИТЕ ХААР УЕЙВЛЕТ- ТРАНСФОРМАЦИИ В ЗАДАЧАТА ЗА ДЕКОДИРАНЕ НА ПРОСТРАНСТВЕНИ ИЗОБРАЖЕНИЯ ПРИ ОТКРИВАНЕ НА СМЕТИЩА
}

\author{
М. Казарян, М. Шахраманян, С. Забунов
}

\begin{abstract}
Резюме
В настоящата статия ние изследваме използването на ортогонални трансформации, а именно основните Хаар уейвлет трансформации с цел обработката на данни от дистанционни изследвания на Земята.

Използва се вътрешната структура на ортогоналните Хаар трансформации. Хаар матрицата се разделя на блокове от един и същи тип, така че да е възможна паралелизация на изчисленията. Установява се целесъобразността на заменяне на спектралните компоненти, съответстващи на целия блок (или няколко блока) на ортогоналната матрица с нули. Проведени са теоретични и експериментални изследвания с цел подобряване на резултатите при класификация на изображения (чрез примери от клъстерния анализ). Коефициентите на разширение на Хаар уейвлета се използват като индикатори при деко-дирането на пространствени изображения в търсенето на сметища.
\end{abstract}


Цел на тази публикация е да опише подхода, на базата на който се установява оптимален метод върху клас от вектори с реални компоненти $\mathrm{X}_{\Delta}=\left\{\bar{x}=\left(x_{0}, \ldots, x_{N-1}\right): \max _{\mathrm{k}}\left|x_{k-1}-x_{k}\right| \leq \Delta\right\}$, приложение на двумерни дискретни Хаар уейвлет трансформации върху задачата за разпознаване на сметища в пространствени изображения.

Обща методология на изследването. Материальт използва елементи на математическия анализ, уейвлет анализа, теорията на дискретните орто-гонални трансформации и методите за декодиране на космически изобра-жения.

Научна новост. Кодирането чрез преобразуване е индиректен метод особено ефективен при обработката на двумерни сигнали, най-вече пространствени изображения, използвани за дистанционни изследвания на Земята.

Ние предлагаме подход, който взема под внимание структурата на Хаар уейвлет матрицата, като в същото време разпознава сметища в пространствени изображения.

Статията обхваща експерименталното приложение на Хаар уейвлет трансформациите за декодиране на пространствени изображения. Ние разглеждаме случаите, както с, така и без техниката на вземане предвид структурата на Хаар уейвлет матриците. 